\title{
DEMYSTIFIED
}

\section{Acid phosphatases}

\section{H Bull, P G Murray, D Thomas, A M Fraser, P N Nelson}

Accepted for publication 20 September 2001

Acid phosphatases (APs) are a family of enzymes that are widespread in nature, and can be found in many animal and plant species. Mystery surrounds the precise functional role of these molecular facilitators, despite much research. Yet, paradoxically, human APs have had considerable impact as tools of clinical investigation and intervention. One particular example is tartrate resistant acid phosphatase, which is detected in the serum in raised amounts accompanying pathological bone resorption. This article seeks to explore the identity and diversity of APs, and to demonstrate the relation between APs, human disease, and clinical diagnosis.

See end of article for authors' affiliations

..........................

Correspondence to: Dr P N Nelson, Biomedical Research Laboratories,

School of Health Sciences, University of

Wolverhampton, 62-68

Lichfield Street,

Wolverhampton WV1 1DJ, UK; P.N.NELSON@

wlv.ac.uk

Dr H Bull, Hyman \&

Clinical Research Group, School of Nursing, University of Nottingham,

Derbyshire Royal Infirmary,

Derby DE 1 2QY, UK
E nzymes are protein molecules that have a three dimensional globular shape. Their function is to speed up the rate at which chemical reactions take place, particularly within the cells of organisms. Enzymes are therefore referred to as biological catalysts. These events take place in the distinct groove or "active site" of the enzyme molecule and involve the binding of the reaction chemical or "substrate", and the breaking or making of chemical bonds. The outcome is a specific change to the substrate, which creates a new chemical molecule or "product". The enzyme molecule itself is unchanged by the event. Enzymes are classified into six groups according to the type of chemical reaction they catalyse (fig 1).

Transferases catalyse the transfer of a small portion (or molecular group) of one substrate on to another, whereas isomerases will convert a molecule into its alternative structural form, called an isomer. Ligases promote bond formation between two substrates, creating one larger molecule. Similarly, oxidases will combine oxygen with the substrate molecule, but can also remove electrons. Lyases encourage specific chemical bonds to break, which enables the substrate molecule to split. Likewise, hydrolases split molecules but, in contrast to lyases, water is always a part of the process. Acid phosphatases (APs) are a family of enzymes that belong to the hydrolase class. They are specifically grouped together because of the shared ability to catalyse the hydrolysis of orthophosphate monoesters under acidic conditions.

\section{ACID PHOSPHATASES}

Despite having a common functional identity, isoenzymes (or different types) of APs differ widely regarding tissue and chromosomal origin, molecular weight, amino acid homology, sequence length, and resistance to $\mathrm{L}(+)$ tartrate and to fluoride. Table 1 compares the characteristics of five important APs found in humans.

Human APs are normally found at low concentrations. However, pronounced changes in their synthesis occur in particular diseases, where unusually high or low enzyme expression is seen as part of the pathophysiological process. This observation suggests that APs could be diagnostically useful as serological and histological markers of disease, and could also be of use in the investigation of the pathophysiology of the associated disease. Table 2 highlights the clinical relevance of five human acid phosphatases as disease markers.

Total lysosomal acid phosphatase (LAP) deficiency is an autosomal recessive disorder that was first discovered by Nadler and Egan. ${ }^{23}$ The clinical features of the disease include intermittent vomiting, lethargy, hypotonia, opisthotona, and terminal bleeding in early infancy. Other case studies have shown LAP deficiency to be limited to white blood cells. This resulted in recurrent infections.

Prostate acid phosphatase (PAP) has been used extensively as a serum marker for cancer of the prostate. It is released into the serum from the prostate gland in increasing amounts as malignant tissue proliferates. In recent years, the enzyme has lost its clinical interest to prostate specific antigen (PSA), which is claimed to be a more sensitive marker for early stage disease. ${ }^{24}$ However, PAP is now receiving renewed interest as a prognostic indicator. ${ }^{15}$ PAP is also released into semen as a normal constituent of seminal fluid. Immunoassays for PAP are still used in forensic investigations as a means of identifying the presence of semen in cases of sexual abuse. ${ }^{25}$

Erythrocyte AP (EAP) is a polymorphic enzyme in humans - there are several gene types or alleles that express the EAP enzyme. A person may inherit the genes for any one of several possible forms of the enzyme. Particular genotypes of EAP are linked with an inherited susceptibility to haemolytic favism, a condition where acute haemolytic anaemia follows the ingestion of fava beans, certain drugs, or particular bacterial or viral infections. Certain genotypes of EAP are also linked to developmental disturbances in childhood. ${ }^{86}$ The existence of alleles for EAP provides six possible genotypes for the enzyme. This

Abbreviations: AP, acid phosphatase; EAP, erythrocyte acid phosphatase; FSD, functional secretory domain; LAP, lysosomal acid phosphatase; OcAP, osteoclast acid phosphatase; PAP, prostate acid phosphatase; PSA, prostate specific antigen; ROS, reactive oxygen species; TRAP, tartrate resistant acid phosphatase 


\section{Enzyme classification}

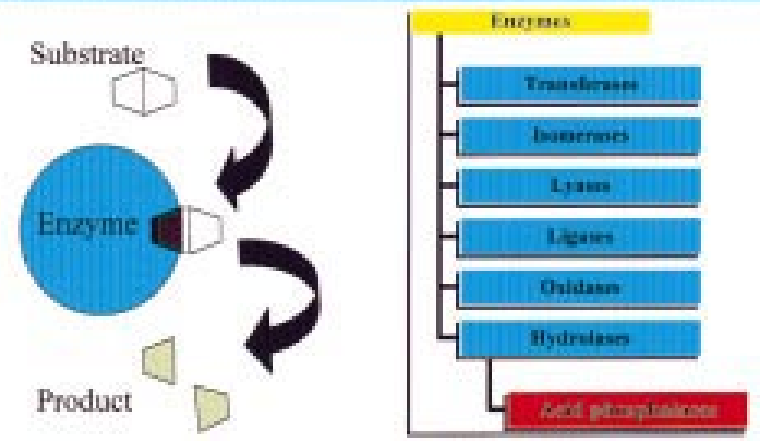

Figure 1 Representation of an enzyme catalysed reaction and the classification of enzymes.

has enabled its exploitation in paternity testing alongside other red cell systems. ${ }^{17}$

"During normal and pathological bone resorption, osteoclastic AP is synthesised in abundance by active osteoclasts of bone tissue"

Gaucher's disease is a inborn error of cerebroside metabolism that is inherited as a recessive disorder. The condition is characterised by the deposition of fatty compounds in the brain and other tissue (especially the bone), which then manifests as mental retardation, abnormal limb posture, spasticity, and difficulty with swallowing. Abnormal macrophages (scavenging cells of the immune system) are a diagnostic trait of Gaucher's disease. These "Gaucher cells" synthesise large amounts of AP, which is easily visualised under the microscope by biochemical staining methods. ${ }^{18}{ }^{19}$ Bone demineralisation is commonly associated with Gaucher's disease and may contribute to the raised concentrations of AP found in the serum of affected individuals. The histological detection of an AP enzyme is also exploited to diagnose leukaemic reticuloendotheliosis, otherwise known as hairy cell leukaemia. The enzyme is expressed in copious amounts by the unusual "hairy cells" of this condition, which are believed to originate from phagocytic B cells. ${ }^{10}$ During normal and pathological bone resorption, osteoclastic AP (OcAP) is synthesised in abundance by active osteoclasts of bone tissue. It is a $35 \mathrm{kDa}$ glycoprotein with a binuclear iron centre at its active site. ${ }^{11}{ }^{12}$ As with the AP found in macrophages, OcAP is a type $5 \mathrm{AP}$ because on polyacrylamide gel electrophoresis it migrates to a fifth position when compared with other APs found in human serum. ${ }^{13}$ Another type $5 \mathrm{AP}$ is found in the serum that is not of bone origin. It is speculated to arise from macrophages ${ }^{27}$ OcAP differs structurally from this isoenzyme by not having sialic acid residues. To highlight this distinction, the type 5 APs from osteoclasts and those of non-bone origin are referred to as APs $5 \mathrm{~b}$ and $5 \mathrm{a}$, respectively. ${ }^{27-29}$ Because of the emerging importance of OcAP for the diagnosis, monitoring, and management of bone resorption pathology, the remainder of this article will focus solely on this particular isoenzyme of acid phosphatase.

\section{TARTRATE RESISTANT ACID PHOSPHATASE OF THE OSTEOCLAST}

Bone growth and remodelling are normal physiological events that occur at a high rate throughout childhood and adolescence, and to a much lesser extent during adult years. It is the net result of the activity of two types of bone cell which have opposing actions: those that synthesise new bone material, mainly, osteoblasts, and cells called osteoclasts, which are responsible for resorbing or breaking down existing bone material.

An exaggerated rate of bone resorption underlies the pathophysiology of many human diseases-for example, Paget's disease, malignant hypercalcaemia, renal osteodystrophy, hyperthyroidism, hyperparathyroidism, and postmenopausal osteoporosis. ${ }^{22}{ }^{30-32}$ The outcome is a progressive thinning of the bones and an increased risk of fractures.

Evidence shows that a pathological increase in bone resorption arises when osteoclasts are stimulated into resorption activity at an increased rate. This upsets the normal balance

Table 1 Characteristics of human acid phosphatases

\begin{tabular}{|c|c|c|c|c|c|c|c|c|}
\hline $\begin{array}{l}\text { Human acid } \\
\text { phosphatase (AP) }\end{array}$ & Tissue/cells cells of origin & $M(k D a)$ & Gel band & Chromosome & $\begin{array}{l}\text { Amino acid } \\
\text { sequence }\end{array}$ & $\begin{array}{l}\text { Amino acid } \\
\text { homology }\end{array}$ & $\begin{array}{l}\text { Tartrate } \\
\text { resistance }\end{array}$ & $\begin{array}{l}\text { Fluoride } \\
\text { resistance }\end{array}$ \\
\hline Lysosomal (LAP) & Most cells' & $100^{1}$ & $3^{2}$ & $11^{1}$ & $423^{3}$ & $50 \% \mathrm{PAP}^{3}$ & - & + \\
\hline Prostatic (PAP) & $\begin{array}{l}\text { Prostate gland, brain, spleen, liver, } \\
\text { platelets }\end{array}$ & $100^{3}$ & $2 b^{5}$ & $3^{3}$ & $345^{3}$ & $50 \% \mathrm{LAP}^{3}$ & - & + \\
\hline Erythrocytic (EAP) & Erythrocytes, many cell types & $18^{6}$ & $1^{2}$ & $2^{7}$ & $157^{8}$ & None known & + & + \\
\hline $\begin{array}{l}\text { Macrophage } \\
\text { (MAP) }\end{array}$ & Macrophages of liver, spleen, lung & $37^{9}$ & $5^{10}$ & $19^{9}$ & $325^{9}$ & $\begin{array}{l}\text { High with } \\
\text { OcAP'12 }\end{array}$ & + & + \\
\hline $\begin{array}{l}\text { Osteoclastic } \\
\text { (OcAP) }\end{array}$ & Osteoclasts of bone & $37^{11}$ & $5^{10}$ & $19^{9}$ & $325^{9}$ & High with MAP 12 & + & - \\
\hline
\end{tabular}

Gel band refers to the relative position of acid phosphatase after its migration towards the cathode in acidic polyacrylamide gel electrophoresis. ${ }^{10} 13$ $M$, molecular mass.

Table 2 Clinical importance of human acid phosphatases

\begin{tabular}{ll}
\hline Human acid phosphatase (AP) & Clinical and laboratory importance \\
\hline Lysosomal (LAP) & LAP deficiency: an inherited autosomal recessive disorder affecting metabolism ${ }^{14}$ \\
Prostatic (PAP) & Serum marker for cancer of the prostate \\
& Semen marker used in forensics for cases of sexual abuse \\
& Increased susceptibility to developmental disturbances and haemolytic favism with certain alleles \\
Erythrocytic (EAP) & Paternity testing \\
& Gaucher's disease: an inborn error of cerebroside metabolism \\
Macrophage (MAP) & Metastasis to the bone ${ }^{20}$ \\
Osteoclastic (OcAP) & Bone resorption conditions \\
&
\end{tabular}

*Relative position of acid phosphatase after its migration towards the cathode in acidic polyacrylamide gel electrophoresis. ${ }^{10} 13$ 

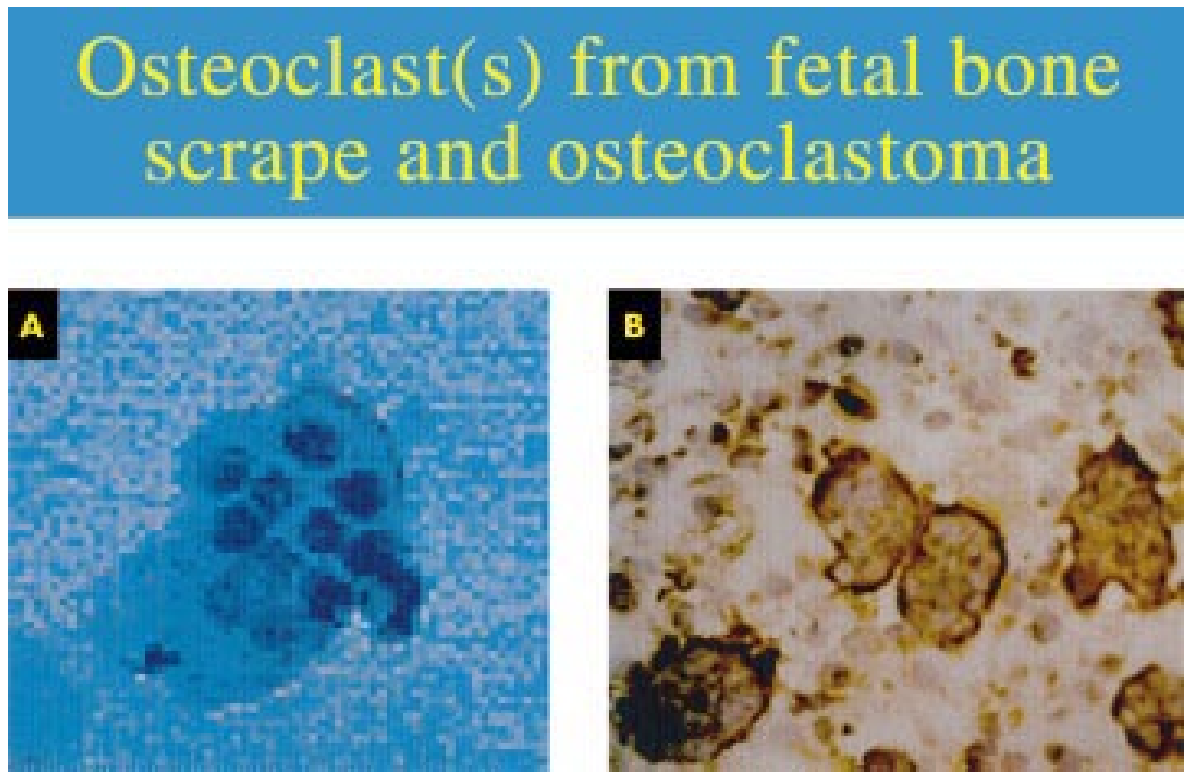

Figure 2 (A) Multinucleated osteoclast (bone scrape) stained with Mayer's haematoxylin (original magnification, $\times 400)$. (B) Monoclonal antibody detecting osteoclasts within an osteoclastoma (substrate, diaminobenzidine).

between bone resorption and bone synthesis. ${ }^{10}$ The increase in osteoclast activity is accompanied by an increase in the synthesis and secretion of type $5 \mathrm{~b}$ AP. This enzyme is resistant to the inhibitory influence that $\mathrm{L}(+)$ tartrate has on the catalytic function of other APs. It is therefore commonly called tartrate resistant acid phosphatase (TRAP). ${ }^{10}$ Evidence indicates that TRAP is involved in the bone resorption process. Furthermore, resorption events are marked by a corresponding rise in the total amount of TRAP in the serum. ${ }^{33}$

An association between osteoclasts and the enzyme TRAP is nothing new. Osteoclasts are well known for containing a large amount of TRAP activity, ${ }^{33}$ and this phenomenon has been used for many years to identify osteoclasts in tissue samples using histochemical techniques. ${ }^{34}$ Further evidence of this association is abundant. For example, (1) osteoclasts cultured in the laboratory on cortical bone slices or dentine show a progressive accumulation of TRAP in the culture medium. This corresponds to the development of resorption lacunae on the bone surface. $^{34}(2)$ Antibodies directed to the active site of TRAP prevent the enzyme carrying out its normal catalytic role. This triggers a decrease in bone resorption. ${ }^{35}$ (3) TRAP "knockout" mice, which do not carry the gene for synthesising TRAP, develop mild osteopetrosis (excessive bone growth) when the balance in bone remodelling is allowed to tilt towards osteoblast activity. ${ }^{36}$ (4) TRAP occurs in much higher concentrations in the serum of people with skeletal disease than in normal control subject. ${ }^{37-39}$ Furthermore, it increases with the rate of resorption taking place. ${ }^{40}$ There is a direct relation between excessive osteoclast facilitated bone resorption and the arrival of increased amounts of TRAP in the circulation. Therefore, serum TRAP has been indicated as a disease associated marker for the clinical diagnosis of excessive bone resorption and for quantitatively monitoring the rate and progression of metabolic bone disorders. ${ }^{33}$

$$
\begin{aligned}
& \text { "Hormones-for example, oestrogen and parathyroid } \\
& \text { hormone-undoubtedly influence the consequent } \\
& \text { resorption activity of osteoclasts" }
\end{aligned}
$$

Measuring the amounts of specific enzymes in the serum has for a long time provided a bedrock for the diagnosis of many commonly encountered clinical conditions. For example, PAP has been used to diagnose cancer of the prostate. Alanine aminotransferase and aspartate aminotransferase are released into the serum from the liver and provide a signal that hepatic cells have been damaged or ruptured. Isotypes of creatine kinase and lactate dehydrogenase are liberated from cardiac cells as a result of cell damage during myocardial infarction. Likewise, TRAP has the potential to be regarded as a diagnostic enzyme and thereby provide valuable information in the routine investigation of pathological bone resorption.

TRAP seeps into the serum after being released from osteoclasts that are actively resorbing bone tissue. The osteoclasts retain their cellular integrity as the enzyme is continually released. Therefore, its raised concentration in the plasma during episodes of pathological bone resorption is not the result of its liberation from damaged cells, as is the case with aspartate aminotransferase, alanine aminotransferase, lactate dehydrogenase, and creatine kinase, as previously mentioned. To trace the route by which TRAP passes before its arrival in the serum, and to unravel the physiological role of TRAP, it is important to appreciate current opinions on how osteoclasts go about resorbing bone tissue.

\section{HOW DO OSTEOCLASTS BREAK DOWN AND REMOVE BONE MATERIAL?}

Osteoclasts are cells of haematopoietic origin that differentiate and migrate to the site of bone resorption, possibly under the influence of cytokines. ${ }^{42-44}$ One osteoclast has many nuclei (fig 2 ). It is believed that this multinuclear structure arises from the fusion of many AP positive mononuclear precursors of osteoclasts. $^{45}$

Hormones-for example, oestrogen and parathyroid hormone-undoubtedly influence the consequent resorption activity of osteoclasts. Immediately before the resorption event, osteoclasts undergo changes by assuming a polarity of structure and function. These changes facilitate bone resorption. ${ }^{46}$ Two distinctive alterations are the development of a ruffled border and a sealing zone at the plasma membrane. This occurs only in the region of the cell that is next to the bone surface. ${ }^{46}$ When osteoclasts arrive at the resorption site they use the sealing zone to attach themselves to the bone surface. Integrins are implicated at the attachment stage, in particular the integrin $\alpha \mathrm{V} \beta 3$, which is expressed by resorbing osteoclasts. Integrins are molecules that enable attachment between two entities, in this case, the bone matrix and the osteoclast. ${ }^{47}$ The ruffled border develops within the sealing 


\section{Osteoclast and bone resorption}

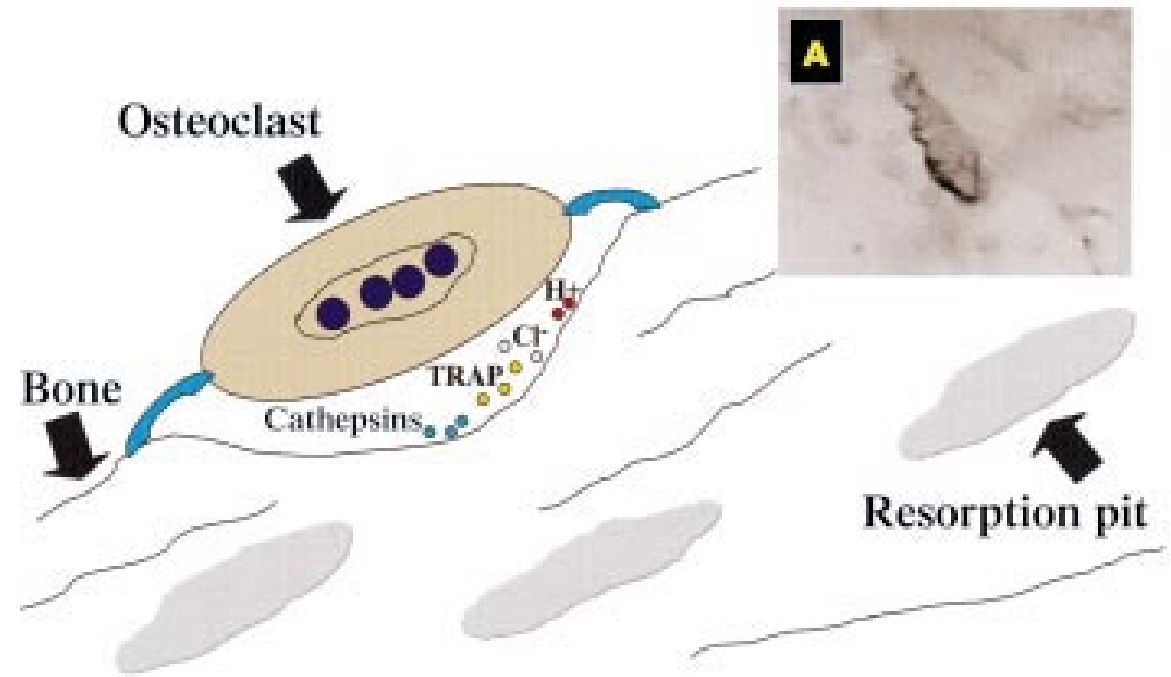

Figure 3 Schematic representation of bone resorption mediated by osteoclasts. (A) An osteoclast at the bone surface where antibody has detected the membrane of the cell. TRAP, tartrate resistant alkaline phosphatase.

zone and is encircled by it. These adaptations form a specialised resorbing organelle, which appears to be made from the fusion of numerous intracellular acidic vesicles. It is located at the region of the plasma membrane that faces the bone. Bone resorption takes place within a microenvironment created beneath these adaptations (fig 3).

\section{Dissolution of hydroxyapatite}

The mineral framework of bone is first dissolved as an initial stage in the breakdown of bone tissue. It is established that mineral dissolution of bone occurs by the action of hydrochloric acid $(\mathrm{HCl})$. The protons for this agent arise from the activity of another enzyme, cytoplasmic carbonic anhydrase II, which is synthesised in large amounts within the osteoclasts. ${ }^{48}$ The protons are then released across the ruffled border into the resorption zone by an ATP consuming proton pump. This culminates in a low $\mathrm{pH}$ of around 2.5-3.0 in the osteoclastic resorption space. ${ }^{49}$ It is notable that metabolic inhibition of the proton pump halts bone resorption. ${ }^{50}$ Therefore, the proton pump appears to be an absolute requirement for normal bone resorption to take place..$^{51}$

\section{Degradation of organic matrix}

The organic constituents of bone tissue remain after the dissolution of the mineralised component. As a second step in bone resorption, proteolytic enzymes are synthesised by osteoclasts and secreted into the sealed resorption zone. Cathepsin K, a proteinase, and matrix metalloprotease 9 (collagenase B) have been identified in particular. ${ }^{52}$ As a result, a visible depression or Howslip's lacuna is excavated into the bone $^{34}$ and forms an extracellular space between the ruffled border membrane and the bone matrix. Until recently, a model had not been formulated that could answer the following questions. How do osteoclasts remove such large amounts of bone matrix from the sealed resorption lacunae during penetrative resorption, without losing their tight grip on the bone? Where do the liberated matrix components go?

\section{Removal of degradation products from resorption lacunae}

Salo et al proposed a model to explain a mechanism. ${ }^{46}$ This was based on experiments that traced the movement of bone matrix components during resorption. Once liberated from the bone, free organic and non-organic particles of the bone matrix were shown to be taken in or endocytosed from the resorption lacunae across the ruffled border into the osteoclast cell. They were then sequestered in membrane bound vesicles within the cytoplasm of the osteoclast. These vesicles and their contents passed across the cell and then fused with a specialised region of the basal membrane called the functional secretory domain (FSD).

Changes in the cytoplasmic framework in this region of the osteoclasts, in particular the disassembly of cortical F-actin network, provided evidence that the discharge or exocytosis of the vesicle contents then took place. Furthermore, clusters of matrix fragments were located in the region directly outside the cell next to the FSD. This supports the view that matrix fragments were finally expelled from the cell by exocytosis into the extracellular space away from the bone. The observation that matrix collagens were trafficked through osteoclasts by way of a transcytotic route is supported by Nesbitt and Horton. ${ }^{47}$ The ultimate fate of resorbing osteoclasts is to undergo apoptosis or cell death. This appears to be triggered when there is a shift from the process of bone resorption to that of formation, as demonstrated in animal models.53

\section{HOW DOES TRAP CONTRIBUTE TO THE BONE RESORPTION PROCESS?}

It has been an enigma how TRAP contributes to this sequence of events and at what stage it participates in the process. Undoubtedly, the rate of TRAP synthesis in osteoclasts and its accumulation in the body fluids has a quantitative association with the rate at which bone resorption is taking place. ${ }^{33}$ This is noted both for normal bone remodelling and the exaggerated activity associated with bone resorption diseases. Therefore, the enzyme is inducible by some kind of trigger and appears to have a direct and/or indirect functional link with the resorption process.

Research indicates that TRAP is synthesised as a latent inactive proenzyme. It is then subsequently made active by having a small region of the molecule cleaved away by another enzyme, a cysteine proteinsases. ${ }^{54}$ Evidence suggests that the active enzyme has a part to play in bone resorption both inside and outside the osteoclast cell. 


\section{Extracellular role of TRAP}

An extracellular role for TRAP during bone resorption is suggested by its extracellular accumulation in the bone matrix immediately next to the ruffled border of resorbing osteoclasts. ${ }^{55}$ However, the precise nature of its catalytic contribution at this site is still unclear, as is its natural substrate.

$$
\begin{aligned}
& \text { "Research indicates that tartrate resistant acid } \\
& \text { phosphatase is synthesised as a latent inactive } \\
& \text { proenzyme" }
\end{aligned}
$$

TRAP is a non-specific phosphatase. It can act on a wide range of natural and synthetic substrates-for example, orthophosphate esters and inorganic pyrophosphates. In vitro studies have established that TRAP can act as a phosphoprotein phosphatase, by catalysing the release of phosphate groups from protein molecules. ${ }^{56}$ This change modifies both the structure and consequently the function of the substrate. ${ }^{57}$ Osteopontin, bone sialoprotein, and osteonectin are bone matrix phosphoproteins that can act as substrates for TRAP. $^{57}$ Osteopontin is a non-collagenous protein that is unevenly distributed during bone resorption. It is highly expressed at the bone surface opposite the sealing zone of resorbing osteoclasts and is essential for resorption to take place.$^{58}$ This bone matrix protein enables osteoclasts to adhere to the bone surface by binding with integrins, in particular $\alpha \mathrm{V} \beta 3$. These integrins are abundantly distributed at the sealing zone of the osteoclast cell itself..$^{59}$ TRAP can remove phosphate groups from osteopontin, an event that consequently disrupts adhesion of osteoclasts to the bone. ${ }^{57}$ This suggests that the enzyme might regulate osteoclast adhesion to the bone and also enable migration of osteoclasts to adjacent sites of resorption-for example. The ability of TRAP to degrade phosphoproteins in bone by dephosphorylation may illustrate a preliminary stage in the degradation of the bone matrix. It would allow specific proteinases to access and then act upon the organic components of bone tissue. Of further interest, the bone matrix is rich in pyrophosphate, a known inhibitor of bone resorption. TRAP can hydrolyse and therefore liberate pyrophosphate from the bone matrix. This hydrolysis event would enable bone resorption activity by osteoclasts to begin.

\section{Intracellular role of TRAP}

Using fluorescence microscopy, Halleen et al localised TRAP within the transcytotic vesicles of osteoclasts, but not at the ruffled border or resorption lacunae. ${ }^{60}$ This last observation is in contrast to Reinholt and colleagues ${ }^{55}$ and Fukushima et al. ${ }^{61}$ At these sites, TRAP was colocalised with the organic products of bone degradation that had been released from bone matrix during resorption and endocytosed into the osteoclast cells. The model was put forward that TRAP containing vesicles from the biosynthetic pathway fuse with transcytotic vesicles transporting matrix degradation products from the ruffled border to the FSD of osteoclasts. At this location, the enzyme is thought to be secreted out of the cells, together with the matrix degradation products. After this stage, both entities leak into the circulation at a rate that corresponds to the amount of resorption activity being undertaken by the osteoclast. The question arises as to the role of TRAP within these vesicles?

The binuclear iron centre that is present at the active site of TRAP conveys catalytic activity on the enzyme molecule. Four states of the enzyme have been identified according to the iron state and the colour of the purified enzyme. These are as follows: purple (inactive), pink (active), yellow (mostly deactivated), and clear (iron free). ${ }^{12}{ }^{56}$ It has been proposed that during TRAP catalysed hydrolysis of phosphomonoesters the iron centre enables the effective binding of a phosphate substrate in the active site in an acid ( $\mathrm{pH} \mathrm{4-6)} \mathrm{environment.} \mathrm{It} \mathrm{is} \mathrm{also}$ thought to promote hydrolysis by means of a potent electron withdrawing effect. ${ }^{62}$ However, evidence is accumulating for a second function for the binuclear iron centre of TRAP, which is the generation of reactive oxygen species (ROS).

Hayman et al found that TRAP could catalyse the formation of free radicals. ${ }^{12} \mathrm{~A}$ free radical is an atom that contains at least one unpaired electron, which makes it very reactive and potentially destructive. Taking this observation further, Halleen et al incubated TRAP in vitro with $\mathrm{H}_{2} \mathrm{O}_{2}$, which produced ROS in the form of hydroxyl radicals.$^{60}$ This strongly suggests that the free radicals arose by way of the well documented Fenton reaction. ${ }^{63}$

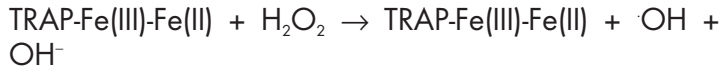

Cultured osteoclast cells, which had been genetically manipulated to overexpress TRAP, produced higher amounts of ROS, demonstrating a link between the amount of TRAP synthesised and the amount of ROS generated.

There is clear evidence that reactive oxygen radicals are required for active resorption at the lacuna. These are produced at the resorptive interface between the bone and the osteoclast. ${ }^{6465}$ ROS are also required for processes within intracellular vesicles of the osteoclast. ${ }^{12}{ }^{60}$ But how do they contribute to this process?

The TRAP derived ROS was seen in vitro to degrade type I collagen to fragments, whereas the TRAP enzyme protein itself was not degraded. ${ }^{60}$ Evidence suggests that a continuous oxidation and reduction of the iron centre of TRAP produced both hydroxyl $(\mathrm{OH})$ and superoxide $\left(\mathrm{O}_{2}{ }^{-}\right)$radicals in these studies. If this oscillation of the iron state took place repeatedly, it would enable a single TRAP molecule to generate a large amount of ROS, providing $\mathrm{H}_{2} \mathrm{O}_{2}$ was present.

\section{"The concentration of tartrate resistant acid phosphatase in the serum appears to have a quantitative and dynamic relation to the amount of resorption taking place on a day by day basis"}

Halleen et al concluded that bone matrix proteins are destroyed within transcytotic vesicles by TRAP facilitated formation of ROS and the subsequent degradation of bone proteins by the ROS generated ${ }^{60}$ However, evidence from this study suggests that TRAP does not have a role in direct excavation of the bone itself, which contradicts previous research findings. These events help explain why the concentration of TRAP increases in the circulation during bone resorption. The enzyme is synthesised to help dispose of the products of bone breakdown within transcytotic vesicles. Along with fragments of bone matrix, it is released into the extracellular environment as an active enzyme by exocytosis at the FSD. TRAP then subsequently leaks into the circulation through the interstitial fluid.

\section{Extracellular fate of TRAP}

Once secreted, the enzyme is exposed to physiological influences present in the body fluids. TRAP has a tendency to bind to and complex with a high molecular weight molecule in serum, namely $\alpha_{2}$ macroglobulin. ${ }^{66}$ Although the role of $\alpha_{2}$ macroglobulin is not clear, it may serve as a carrier and a regulator of cytokine activity. ${ }^{67}$ Therefore, it is feasible that it is also a carrier molecule for TRAP that mediates the clearance of the enzyme from areas of bone resorption and then the circulation. Ultimately, TRAP has the fate of all circulating enzymes. Its structure becomes compromised, leading to its inactivation as a catalyst. It loses its binuclear iron centre, which is then recycled, and the iron free enzyme protein is broken down by proteases in the plasma and the liver. The 
Table 3 Serum tartrate resistant acid phosphatase

\begin{tabular}{|c|c|c|c|}
\hline \multirow[b]{2}{*}{ Subject group } & \multicolumn{3}{|c|}{ Serum concentrations of TRAP measured by immunoassay } \\
\hline & $\begin{array}{l}\text { Cheung and } \\
\text { colleagues }^{37} \\
\text { ( } \mu \mathrm{g} / \mathrm{l} ; \text {; range) }\end{array}$ & $\begin{array}{l}\text { Chamberlain and } \\
\text { colleagues }{ }^{39} \\
(\mu \mathrm{g} / \mathrm{l} \text { (mean }(\mathrm{SD}))\end{array}$ & $\begin{array}{l}\text { Halleen and } \\
\text { colleagues } \\
(\mu \mathrm{g} / \mathrm{l} ; \text { mean }(\mathrm{SD}))\end{array}$ \\
\hline \multicolumn{4}{|l|}{ Normal } \\
\hline Men & $61-301$ & $3.15(1.6)$ & \\
\hline Children & $401-712$ & & \\
\hline Women (premenopause) & $41-288$ & $3.7(1.8)$ & $7.9(2.8)$ \\
\hline \multicolumn{4}{|l|}{ Clinical } \\
\hline Women (postmenopause) & $129-348$ & $6.3(2.3)$ & $11.0(3.4)$ \\
\hline
\end{tabular}

fragments that result from these events are eventually metabolised by the liver and/or removed in the urine. Experiments performed by Halleen et al give some indication of the time scale of TRAP activity. ${ }^{56}$ Inactive, human osteoclast derived TRAP, equivalent to newly synthesised enzyme, required four hours' incubation at $37^{\circ} \mathrm{C}$ to convert to the active pink form. Deactivating the enzyme to the yellow form required 24 hours' incubation. These results have implications for the dynamic testing of bone resorption using a serum sample. Quantities of active TRAP measured in the serum could indicate the amount of osteoclast activity taking place no longer than 24 hours before sampling.

\section{CLINICAL USEFULNESS OF TRAP AND OSTEOCLAST FUNCTION}

Taken as a whole, these findings have uncovered a direct involvement of TRAP in the pathology of bone resorption conditions. Furthermore, its concentration in the serum appears to have a quantitative and dynamic relation to the amount of resorption taking place on a day by day basis. This has important implications for the diagnosis, management, and treatment of excessive loss of bone tissue in certain disease states.

\section{Clinical intervention to slow down or prevent pathological bone resorption}

The pathway of both osteoclast function and TRAP activity exposes stages in the process of bone resorption that can be targeted for clinical intervention. The controlling influence of particular hormonal triggers on the increase and suppression of bone resorption have been pursued. For example, hormone replacement therapy increases serum concentrations of oestrogen as a prophylactic measure against the development of postmenopausal osteoporosis ${ }^{68}$; bisphosphonates such as alendronate can suppress parathyroid hormone mediated bone resorption $^{69}{ }^{70}$; and interferon $\gamma$ was shown to prevent osteoclast differentiation into active, TRAP producing cells. ${ }^{71}$ Inhibitors of osteoclast integrins are being explored to prevent the attachment of osteoclasts to bone before the synthesis of TRAP and its release. ${ }^{72}$ It is interesting that fluoride, which is currently used as a compound in the treatment of osteoporosis, ${ }^{73}$ is a known inhibitor of TRAP enzyme activity. ${ }^{4}$ It is possible that this agent has its positive effects not only by its well documented effect on bone hydroxyapatite but also by the inhibition of TRAP.

\section{Diagnosis of excessive bone resorption and dynamic monitoring of bone loss during disease management regimens}

As with the development of many clinical tests now in routine use, the development of a reliable assay for measuring serum TRAP values has been a steady, evolving process, which has not been perfect from the start. It has needed progressive fine tuning as more has become known about the physiology and biochemistry of the TRAP molecule and the requirements of immunoassay protocols to measure it.

Immunoassays have provided the most promise as diagnostic tools for detecting osteoclast derived TRAP in serum. This methodology can potentially sensitively measure the amount of TRAP protein present in a millilitre of serum. The technique offers a solution to the problems associated with the "older" enzyme activity methods that measured the catalytic activity of total TRAP present in the serum, regardless of its cellular origins. Table 3 shows the concentration of TRAP found in the serum of healthy and postmenopausal subjects as measured by three different immunoassay protocols.

A detectable increase in serum TRAP concentration in children and postmenopausal women is illustrated, as compared with healthy adults. However, disagreements between research groups are clearly evident and may arise because of the use of different immunoreagents and immunoassay protocols.

Isotypes of TRAP are functionally akin. However, they can be very different in molecular structure. A reliable immunoassay for measuring TRAP in the serum needs to exploit unique structural traits of the osteoclast derived TRAP molecule to discriminate it from other serum components. Monoclonal antibodies are fundamental to immunoassay methodology. The specificity and sensitivity of an immunoassay is reliant upon the availability of monoclonal antibodies that possess the highest power to differentiate between isotypes of APs and TRAPs. Therefore, these reagents require stringent development to ensure that they bind exclusively to a particular epitope (small region) on the osteoclast derived TRAP molecule. ${ }^{74-76}$ This could be one factor causing the discrepancy between immunoassays for TRAP that are currently being developed. The hybridoma technique of monoclonal antibody development has the potential to provide an unlimited supply of a monoclonal reagent to osteoclast derived TRAP. Reagents that are developed with this technique-for example, by using synthetic peptides (representing key antigenic determinants) for immunisation-will possess exquisite specificity for epitopes on the enzyme molecule. ${ }^{77}$

Measurement of serum TRAP has yet to achieve the clinical acceptance associated with other established markers of bone resorption. ${ }^{78}{ }^{79}$ However, a reliable immunoassay for TRAP would improve the identification and monitoring of bone resorption activities of osteoclasts. Such an assay would compliment established methods that use bone degradation products as markers in the urine-for example, deoxypyridinium crosslinks and their associated peptides ${ }^{80}{ }^{81}$ Diagnostic protocols using urine as a sample medium require a 24 hour collection and need correlating to creatinine. This can be both impractical and labourious. Furthermore, urine as a sample medium can present high analytical and biological variation. A serum based immunoassay is therefore preferential. 


\section{Take home messages}

- Alkaline phosphatases (APs) catalyse and facilitate important physiological changes within cells and their expression is altered in many disease processes

- Tartrate resistant AP of the osteoclast (TRAP) plays an important role in bone resorption. Although the details of the mechanism are still unclear, in the future it may be possible to interfere with the osteoclast/TRAP system to manipulate pathological processes and reduce the loss of bone density

- TRAP has been useful in the histological diagnosis of hairy cell leukaemia, Gaucher's disease, and osteoclastoma

- Because the concentration of TRAP in serum is directly associated with osteoclast mediated bone resorption, serum TRAP measurement would be useful in the diagnosis and monitoring of bone resorption conditions if assay methods could be adapted for use with a serological medium

\section{CONCLUSION}

This article highlights several important points that provide a rationale for taking APs more seriously in the diagnosis, management, and treatment of clinical conditions.

APs catalyse and facilitate important physiological changes within cells. These are strikingly evident when APs are deficient or expressed in excessive amounts (table 2). Distinct stages of osteoclast/TRAP mediated bone resorption are being clarified and present opportunities to manipulate pathological processes, decrease the loss of bone density, and reduce the risk of fractures. Questions remain to be answered such as the identity of cytokines that control the process of TRAP synthesis and activity. However, measures to inhibit the action of intracellular TRAP could hamper the removal of degradation products, with the deleterious prospect of "clogging up" the system, or the beneficial imposition of a rate limiting influence on the resorption process.

The TRAP molecule itself has already had unquestionable impact on the histological diagnosis of hairy cell leukaemia, Gaucher's disease, and osteoclastoma. It has the potential to influence the diagnosis of bone resorption conditions if assay methods are adapted for use with a serological medium. Tartrate resistant AP 5b meets the essential criteria for a serum marker of disease. It has unique structural features allowing it to be distinguished from other molecules, isotypes of AP, and from degradation fragments of TRAP present in the serum; it is released into plasma at a rate proportional to the pathological event it is associated with; it is measurable in the plasma; it is stable on storage; and it can provide a dynamic profile of pathological changes taking place on a day by day basis.

An immunoassay for measuring TRAP as an indication of the amount of bone resorption taking place would provide additional information in the hospital clinical laboratory for the diagnosis and monitoring of bone resorption conditions. In addition, there is the prospect of simplifying the test for self monitoring as an "over the counter kit", as is available for blood glucose, blood cholesterol, and pregnancy testing. The kit could provide regular feedback for people at risk of bone loss, and who are attempting to take control of it themselves through exercise, diet, alternative treatments, and conventional regimens.

\section{Authors' affiliations}

H Bull, Human and Clinical Research Group, School of Nursing University of Nottingham, Derbyshire Royal Infirmary, Derby DE 1 2QY, UK

D Thomas, A M Fraser, Biomedical Research Laboratories, School of Health Sciences, University of Wolverhampton, 62-68 Lichfield Street, Wolverhampton WV1 1DJ, UK

P G Murray, Department of Pathology, Division of Cancer Studies, University of Birmingham, Birmingham B15 2TT, UK
A M Frazer Orthopaedic Department, New Cross Hospital, Wednesfield Road, Wolverhampton WV10 OQP, UK

\section{REFERENCES}

1 Pohlmann R, Krentler C, Schmidt B. Human lysosomal acid phosphatase: cloning, expression and chromosomal assignment. EMBO J 1998;7:2343-50.

2 Moss DW, Raymond FD, Wile DB. Clinical and biological aspects of acid phosphatase. Crit Rev Clin Lab Sci 1995;32:431-67.

3 Sharief FS, Lee $H$, Lauderman $M M$, et al. Human prostatic acid phosphatase: cDNA cloning gene mapping and protein sequence homology with lysosomal acid phosphatase. Biochem Biophys Res Commun 1989;160:79-86.

4 Nakanishi M, Yoh K, Uchida K, et al. Improved method for measuring tartrate-resistant acid phosphatase activity in serum. Clin Chem 1998:44:221-5

5 Lam K-W, Li CY, Yam LT. Comparison of prostatic and nonprostatic acid phosphatase. Ann N Y Acad Sci 1982;390: 1-5

6 Dissing J, Svensmark O. Human red cell acid phosphatase: purification and properties of A, B and C isozymes. Biochim Biophys Acta 1990;1041:232-42.

7 Wo YY, McCormack AL, Shabanowitz J, et al. Sequencing, cloning and expression of human red cell-type acid phosphatase, a cytoplasmic phosphotyrosyl protein phosphatase. J Biol Chem 1992;267: 10856-65.

8 Bottini E, Gloria-Bottinin F, Borgiani P, et al. ACP1 and human adaptability. 1. Association with common diseases: a case-control study Hum Genet 1995;96:629-37

9 Lord DK, Cross NCP, Bevilacque MA. Sequence, expression and chromosomal localisation of a differentiation-associated protein of the human macrophage. Eur J Biochem 1990;189:287-93.

10 Yam LT. Clinical significance of human acid phosphatases. Am J Med 1974;56:604-16.

11 Hayman AR, Warburton M, Pringle JAS. Purification and characterisation of a tartrate-resistant acid phosphatase from human osteoclastomas, Biochem J 1989:261:601-9.

12 Hayman AR, Cox TM. Purple acid phosphatase of the human macrophage and osteoclast. J Biol Chem 1994;269:1294-300.

13 Lam WKW, Lai LC, Yam LT. Tartrate-resistant (band 5) acid phosphatase activity measured by electrophoresis on acrylamide gel. Clin Chem 1978:24:309-12.

14 Nadler HL, Egan TJ. Deficiency of lysosomal acid phosphatase. A new familial metabolic disorder. N Engl J Med 1970;282:302-7.

15 Dattoli M, Wallner K, True L, et al. Prognostic role of serum prostatic acid phosphatase for 103Pd-based radiation for prostatic carcinoma. Int J Radiat Oncol Biol Phys 1999;45:853-6.

16 Allen SM. An enzyme linked immunosorbent assay (ELISA) for detection of seminal fluid using a monoclonal antibody to prostatic acid phosphatase. J Immunoassay 1995;16:297-308.

17 Minakata K. Asano M. A case study of paternity diagnosis where phenotypes $C A$ and $C B$ of erythrocyte acid phosphatase were found in a putative father and a child, respectively. Nippon Hoigaku Zasshi 1986;40:146-9

18 Robinson DB, Glew RH. Acid phosphatase in Gaucher's disease. Clin Chem 1980;26:371-82.

19 Giraldo P, Pocovi M, Perez-Calvo J, et al. Report of the Spanish Gaucher's disease registry: clinical and genetic characteristics. Haematologica 2000;85:792-9.

20 Wada N, Ussguu S, Ikeda T, et al. Serum tartrate resistant acid phosphatase as a potential marker of bone metastasis from breast cancer. Anticancer Res 1999;19:4514-22.

21 Wada N, Fujisaki $M$, Ishii $S$, et al. Evaluation of bone metabolic markers in breast cancer with bone metastasis. Breast Cancer 2001;8:131-7.

22 Coen G, Ballanti $\mathrm{P}$, Bonucci $\mathrm{E}$, et al. Bone markers in the diagnosis of low turnover osteodystrophy in haemodialysis patients. Nephrol Dial Transplant 1998;13:2294-302.

23 Nadler HL, Egan TJ. Deficiency of lysosomal acid phosphatase. A new familial metabolic disorder. N Engl J Med 1970;282:302-7.

24 Akimoto S, Furuya Y, Akakura K, et al. Relationship between prostate-specific antigen, clinical stage, and degree of bone metastasis in patients with prostate cancer: comparison with prostatic acid phosphatase and alkaline phosphatase. Int J Urol 1997;6:572-5

25 Allen SM. An enzyme linked immunosorbent assay (ELISA) for detection of seminal fluid using a monoclonal antibody to prostatic acid phosphatase. J Immunoassay 1995;16:297-308.

26 Bottini E, Lucarelli P, Agostino R, et al. Favism: association with erythrocyte acid phosphatase phenotype. Science 1971;171:409-11.

27 Halleen JM, Alatalo SL, Suominen H, et al. Tartrate-resistant acid phosphatase 5b: a novel serum marker of bone resorption. J Bone Miner Res 2000;15:1337-45

28 Janckila AJ, Takahashi K, Sun SZ, et al. Naphthol-ASBI phosphate as a preferred substrate for tartrate-resistant acid phosphatase isoform $5 \mathrm{~b}$. $J$ Bone Miner Res 2001;16:788-93.

29 Alatalo SL, Halleen JM, Hentunen TA, et al. Rapid screening method for osteoclast differentiation in vitro that measures tartrate-resistant acid phosphatase $5 \mathrm{~b}$ activity secreted into the culture medium. Clin Chem 2000;46: 1751-4.

30 Katagiri $M$, Ohtawa T, Fukunagaa $M$, et al. Evaluation of bone loss and serum markers of bone metabolism in patients with hyperparathyroidism. Surg Today 1995;25:598-604. 
31 Torress $\mathbf{R}$, de la Piedra C, Rapado A. Clinical usefulness of serum tartrate-resistant acid phosphatase in Paget's disease of bone: correlation with other biochemical markers of bone remodelling. Calcif Tissue Int 1991;49:14-16

32 de la Piedra Gordo C, Torres Jimenez R. Usefulness of bone remodelling biochemical markers in the diagnosis and follow-up of Paget's bone disease, primary hyperparathyroidism, tumor hypercalcemia and postmenopausal osteoporosis II bone resorption markers. An Med Interna 1991;7:534-8.

33 Minkin C. Bone acid phosphatase: tartrate-resistant acid phosphatase as a marker of osteoclast function. Calcif Tissue Int 1982:34:285-90.

34 Kaye M. When is it an osteoclast? J Clin Pathol 1984;37:398-400.

35 Zaidi M, Moonga B, Moss DW, et al. Inhibition of osteoclastic acid phosphatase abolishes bone resorption. Biochem Biophys Res Commun 1989;159:68-71.

36 Hayman AR, Jones SJ, Boyde A, et al. Mice lacking tartrate-resistant acid phosphatase (ACP5) have disrupted endochondral ossification and mild osteopetrosis. Development 1997;122:3151-62.

37 Cheung CK, Panesar NS, Haines C, et al. Immunoassay of a tartrate resistant acid phosphatase in serum. Clin Chem 1995:41:679-86.

38 Halleen JM, Karp M, Viloma S, et al. Two-site immunoassays for osteoclastic tartrate-resistant acid phosphatase based on characterisation of six monoclonal antibodies. J Bone Miner Res 1999; 14:464-9.

39 Chamberlain P, Compston J, Cox TM, et al. Generation and characterisation of monoclonal antibodies to human type-5 tartrate-resistant acid phosphatase: development of a specific immunoassay of the isoenzyme in serum. Clin Chem 1995;41:1495-9.

40 Lau KHW, Onishi T, Wergedal JE, et al. Characterisation and assay of tartrate-resistant acid phosphatase activity in serum: potential use to assess bone resorption. Clin Chem 1987;33:458-62.

41 Rico H, Villa LF. Serum tartrate resistant acid phosphatase (TRAP) as a biochemical marker of bone remodelling. Calcif Tissue Int 1993;52:149-50.

42 Atkins GJ, Haynes DR, Geary SM, et al. Coordinated cytokine expression by stromal and hematopoietic cells during human osteoclast formation. Bone 2000;26:653-6.

43 Azuma Y, Kaji K, Katogi R, et al. Tumor necrosis factor-alpha induces differentiation of and bone resorption by osteoclasts. J Biol Chem 2000;275:4858-64

44 Manolagas SC. The role of IL-6 type cytokines and their receptors in bone. Ann N Y Acad Sci 1998;840:194-204.

45 Takeshita S, Kaji K, Kudo A. Identification and characterisation of the new osteoclast progenitor with macrophage phenotypes being able to differentiate into mature osteoclasts. J Bone Miner Res 2000:15: 1477-88.

46 Salo J, Lehenkari P, Mulari M, et al. Removal of osteoclast bone resorption products by transcytosis. Science 1997;276:270-3.

47 Nesbitt SA, Horton MA. Trafficking of matrix collagens through bone-resorbing osteoclasts. Science 1997;276:266.

48 Biskobing DM, Fan D. Acid pH increases carbonic-anhydrase II and calcitonin receptor mRNA expression in mature OC. Calcif Tissue Int 2000;67:178-83.

49 Marshall K, Nash K, Haussman G, et al. Recombinant human and mouse purple acid phosphatases: expression and characterisation. Arch Biochem Biophys 1997;345:230-6.

50 Sundquist K, Lakkakorpi P, Wallmark B, et al. Inhibition of osteoclast proton transport by bafilomycin Al abolishes bone resorption. Biochem Biophys Res Commun 1990;168:309-13.

51 Li YP, Chen W, Liang Y, et al. Atp6l-deficient mice exhibit severe osteopetrosis due to loss of osteoclast-mediated extracellular acidification. Nat Genet 1999;23:4447-51.

52 Dodds RA, James JE, Rieman D, et al. Human osteoclast cathepsin K is processed intracellularly prior to attachment and bone resorption. J Bone Miner Res 2001;16:478-86.

53 Kobayashi $\mathbf{Y}$, Hashimoto F, Miyamoto $\mathrm{H}$, et al. Forced inducted osteoclasts apoptosis in vivo accompanied by elevation in transforming growth factor beta and osteoprotegrin expression. J Bone Miner Res 2000;15:1924-1934.

54 Ljusberg J, Ek-Rylander B, Andersson G. Tartrate-resistant purple acid phosphatase is synthesised as a latent proenzyme and activated by cysteine proteinases. Biochem J 1999;343:63-9.

55 Reinholt FP, Mengarelli-Widholm S, Ek-Rylander B, et al.. Ultrastructura localisation of tartrate-resistant acid ATPase in bone. J Bone Miner Res 1990;5:1055-61.
56 Halleen JM, Jaija H, Stepan JJ, et al. Studies on the protein tyrosine phosphatase activity of tartrate-resistant acid phosphatase. Arch Biochem Biophys 1998;352:97-102

57 Ek-Rylander B, Flores $M$, Wendal M, et al. Dephosphorylation of osteopontin and bone sialoprotein by osteoclastic tartrate-resistant acid phosphatase. Modulation of osteoclast adhesion in vitro. J Biol Chem 1994;269: 14853-6.

58 Asou $\mathrm{Y}$, Rittling SR, Yoshitake $\mathrm{H}$, et al.. Osteopontin facilitates angiogenesis, accumulation of osteoclasts, and resorption in ectopic bone. Endocrinology 2001;142:1325-32.

59 Flores ME, Norgard M, Heinegard D. RGD-directed attachment of isolated rat osteoclasts to osteopontin, bone sialoprotein, and fibronectin. Exp Cell Res 1992:201:526-30.

60 Halleen JM, Saisanen S, Salo J, et al. Intracellular fragmentation of bone resorption products by reactive oxygen species generated by osteoclastic tartrate-resistant acid phosphatase. J Biol Chem 1999;274:22907-10

61 Fukushima O, Bekker PJ, Gay CV. Ultrastructural localisation of tartrate-resistant acid phosphatase (purple acid phosphatase) activity in chicken cartilage and bone. Am J Anat 1991;191:228-36.

62 Kawabe H, Sugiura Y, Terauchi $M$, et al. Properties of Fe(III)-substituted enzyme and function of $\mathrm{Mn}$ (III) and $\mathrm{Fe}(\mathrm{III})$ in plant and mammalian acid phosphatase. Biochim Biophys Acta 1984;784:81-79.

63 Henle ES, Luo Y, Lin S. Fe2+. Fe3+ and oxygen react with DNA-derived radicals formed during iron-mediated Fenton reaction. Biochemistry 1996:35:12212-19.

64 Darden AG, Ries WL, Wolf WC, et al. Osteoclastic superoxide production and bone resorption: stimulation and inhibition by modulators of NADPH oxidase. J Bone Miner Res 1996;1 1:671-75.

65 Key LL, Jr, Ries WL, Taylor RG, et al. Oxygen derived free radicals in osteoclasts: the specificity and location of the nitroblue tetrazolium reaction. Bone 1990;11:115-19.

66 Brehme CS, Roman S, Shaffer J, et al. Tartrate-resistant acid phosphatase forms complexes with $\alpha$-macroglobulin in serum. J Bone Miner Res 1999;14:311-18.

67 Chu CT, Pizzo SC. Alpha2-macroglobulin, complement and biologic defence: antigens, growth factors microbial proteases and receptor ligation. Lab Invest 1994;71:792-812.

68 Lees B, Stevenson JC. The prevention of osteoporosis using sequential low-dose hormone replacement therapy with estrodiol-17 beta and dydrogesterone. Osteoporos Int 2001;12:251-8.

69 Rossini M, Gatti D, Isaia G, et al. Effects of oral alendronate in elderly patients with osteoporosis and mild primary hyperparathyroidism. J Bone Miner Res 2001;16:113-19.

70 Watanabe J, Amizuka N, Noda T, et al. Cytochemical and ultrastructural examination of apoptotic odontoclasts induced by bisphosphonate administration. Cell Tissue Res 2000;301:375-87.

71 Kamolmatyakul S, Chen W, Li YP. Interferon-gamma down-regulates gene expression of cathepsin $\mathrm{K}$ in osteoclasts and inhibits osteoclast ormation. J Dent Res 2001;80:351-5.

72 Hartman GD, Duggan ME. Alpha (v)beta(3) integrin antagonists as inhibitors of bone resorption. Expert Opinion on Investigational Drugs 2000;9:1281-91.

73 Duursma SA, Raymakers JA. Fluoride treatment: a good choice in osteoporosis. Ned Tijdschr Geneeskd 1998;142:1902-3.

74 Bull H, Choy M, Manyonda I, et al. Reactivity and assay restriction profiles of monoclonal and polyclonal antibodies to acid phosphatase: a preliminary study. Immunol Lett 1999;70:143-9.

75 Nelson PN, Pringle JAS, Chambers TJ. Production and characterisation of new monoclonal antibodies to human osteoclasts. Calcif Tissue Int 1991:49:317-20

76 Nelson PN, Chambers T. Generation and characterisation of putative monoclonal and polyclonal antibodies against tartrate-resistant acid phosphatase. Hybridoma 1995;14:91-4.

77 Nelson PN, Reynolds GM, Waldron EE, et al. Monoclonal antibodies. J Clin Pathol Mol Pathol 2000:53:111-17.

78 Rosalki SB. Biochemical markers of bone turnover. Int J Clin Pract 1998;52:255-6.

79 Withold W. Monitoring of bone turnover: biological, preanalytical and technical criteria in the assessment of biochemical markers. Eur J Clin Chem Clin Biochem 1996:34:785-99.

80 Seibel MJ, Woitge HW. Basic principles and clinical applications of biochemical markers of bone metabolism. Journal of Clinical Densitometry 1999;2:299-321.

81 Szulc P, Seeman E, Delmas PD. Biochemical measurements of bone turnover in children and adolescents. Osteoporos Int 2000;11:281-94. 